\title{
DiOLTOS
}

\section{Comunicación y acción colectiva. Estudio de caso de la resonancia en estudiantes universitarios de los marcos movilizadores de Anonymous}

Communication and collective action. Case study of the resonance in university students of the mobilizing frameworks of Anonymous

\author{
Rodrigo Perera Ramos \\ pererarodrigo@gmail.com \\ Universidad Nacional Autónoma de México
}

Recibido: 2018-12-07

Aceptado: 2019-04-14

\section{Resumen}

En este artículo se analiza Internet como una herramienta de automediación de los movimientos sociales (MS), la cual, mediante su uso y apropiación por parte de los activistas, pudiera coadyuvar a una comunicación más resonante de los marcos de acción colectiva (MAC) en las audiencias de los MS. Para ello, se retoman conceptos tanto de la subdisciplina de la acción colectiva y los MS, como de la comunicación, los cuales fueron operacionalizados a través de un estudio de caso en el que se hace un análisis estadístico a partir de tres categorías analíticas (marco de injusticia, identidad y agencia) y tres dimensiones analíticas (cognitiva, afectiva y participativa), con el fin de medir la resonancia de Anonymous en estudiantes mexicanos y hacer inferencias sobre ello. Por último, el artículo también propone que los niveles de apropiación de la

\begin{abstract}
In this article the Internet is analyzed as a tool for self-mediation of social movements, which through its use and appropriation by activists could contribute to a more resonant communication of their collective action frameworks in their audiences; in order to do this, concepts of the subdiscipline of collective action and social movements, as well as of communication, are brought back operationalizing them through a case study, in which a statistical analysis is made from three analytical categories (injustice, identity and agency frames) and three analytical dimensions (cognitive, affective and participative), in order to measure the resonance of Anonymous in Mexican students and make inferences about it. Finally, the article also proposes that the appropriation levels of the Information and Communication
\end{abstract}


Tecnologías de la Información y la Comunicación (TIC), por parte de las audiencias y de los propios grupos reivindicativos, es una mediación que juega un rol importante y que es directamente proporcional en la resonancia de los MAC, diseminados preponderantemente a través del ciberespacio.

\section{Palabras clave}

Movimientos sociales, resonancia, audiencias, mediaciones, apropiación tecnológica.
Technologies by the audiences and by the protest groups is a mediation that plays an important and directly proportional role in the resonance of the frames, which are predominantly disseminated through the cyberspace.

\section{Introducción}

Este artículo se enfoca en la discusión sobre la apropiación de las TIC, por parte de los grupos contenciosos, y parte del supuesto de que estas tecnologías podrían amplificar las oportunidades estructurales de mediación de los MS y de esta forma romper con la lógica de dependencia de estos con los medios de comunicación tradicionales. El trabajo sugiere que los MS podrían tener una mayor capacidad resonante en sus auditorios, a través de procesos de automediación habilitados por las tecnologías digitales y en particular Internet.

El documento parte de vincular la teoría de los MAC y de las identidades colectivas, con la de los estudios culturales de la comunicación. Para ello, retoma conceptos teóricos de los estudios de la comunicación y de la sociología de la acción colectiva, como lo son los de resonancia, enmarcado, mediaciones, apropiación y audiencias.

Con base en la argumentación teórica, la investigación empírica que se desarrolla, sustentada en un estudio de caso simple, tiene como objetivo el de medir la resonancia del MAC de Anonymous en una audiencia que se pensó como la ideal del colectivo (dentro de las posibilidades estructurales de la pesquisa), con la finalidad de presentar evidencia empírica que pueda coadyuvar al tema de investigación, que aquí se presenta.

En este sentido, Anonymous se observa, en este estudio, como una identidad colectiva de la movilización social idónea para adentrarse en la discusión teórica-empírica sobre el impacto que están teniendo las TIC, en particular Internet, en los MS.

Un segundo objetivo que se persigue es el de analizar cuáles son las mediaciones más significativas, desde el punto de vista estadístico, que permitan explicar las variaciones en el nivel de resonancia de las audiencias con respecto al MAC. 
Asimismo, el artículo presenta una breve descripción de Anonymous y su MAC, como resultado de una observación indirecta (de tipo documental, con fuentes secundarias) y de un análisis del discurso. Este último también se realizó con el fin de construir el instrumento para la recolección de datos cuantitativos, la ponderación de algunos de sus resultados y su interpretación. Por tanto, la indagación que se reporta está basada en una estrategia metodológica mixta. El objetivo de presentar en este articulo algunos de los hallazgos de la investigación cualitativa es con el fin de contextualizar a los lectores sobre el actor colectivo del estudio de caso.

Por último, la investigación parte de la hipótesis de que el nivel de apropiación de las TIC es una mediación (tanto para el actor colectivo, como para sus audiencias) que guarda una relación directa con el grado de resonancia de los MAC, el artículo se enfoca en comprobar esta hipótesis en el campo de identidad de las audiencias y se presupone que es inédita al no encontrar, durante el estudio del estado del arte, alguna hipótesis similar, con respecto al objeto de estudio de esta investigación (la resonancia de los MAC, en las audiencias de los MS, automediados por Internet).

\section{Comunicación y acción colectiva}

La relación entre la comunicación y el enmarcado de los sistemas de acción colectiva, es decir, de redes complejas de relaciones entre niveles y significados diversos de la acción social, como define Melucci (2001) a los MS, ha sido estudiada desde la década de 1970 con trabajos representativos como los de Halloran, Elliott y Murduck (1970), Gitlin (1980), Van Zoonen (1992), Ashley y Olson (1998) y Oliver y Maney (2000).

Todos estos trabajos, citados en el párrafo anterior, coinciden en la existencia de una relación de dependencia y asimétrica entre los medios de comunicación masiva y los MS, en la cual (ya sea por las rutinas del periodismo, los formatos y lenguajes propios de cada medio, por el tratamiento y selección de la información o por motivos ideológicos) las redes de acción colectiva son presentadas en el mainstream mediático como violentas, anárquicas y de manera superficial. En estos medios, concluyen los autores, es encuadrado lo dramático, lo espectacular y lo conflictivo de las identidades colectivas, a su vez que son marginadas las cuestiones de fondo de los movimientos, el contexto en el que se da el conflicto y, principalmente, el enmarcado o MAC de los grupos contenciosos, a través de los cuales expresan su identidad, agravios, asignan culpabilidad a la situación, así como los medios y fines de la acción.

En suma, con base en la idea de que los MAC son una deconstrucción y reconstrucción simbólica del discurso dominante, la mediación de los MS, a través de los mass media, es caracterizada (al menos durante el siglo XX) por no presentar o mediatizar de forma favorable, o al menos imparcial, a estas identidades colectivas de la movilización social, a partir de los procesos de recodificación del enmarcado colectivo en los medios tradicionales. Sin embargo, investigaciones más recientes, como la de Cammaerts (2012), concluyen que el mainstream mediático no siempre trata negativamente a los movimientos de protesta y a la acción directa. 
Perera Ramos, R. (2019)

Comunicación y acción colectiva. Estudio de caso de la resonancia en estudiantes universitarios de los marcos movilizadores de Anonymous

pp. $75 / 107$

En efecto, pareciera que la relación entre medios masivos de comunicación y MS se está transformado en este siglo y está pasando de una relación verticalizada y de dependencia, hacia una de interdependencia, más simétrica y horizontal. Lo anterior pudiera interpretarse como una consecuencia de la expansión de Internet y la apropiación de esta tecnología por parte de los actores colectivos reivindicativos, lo cual los ha empoderado al romper su dependencia con los medios masivos de comunicación tradicionales (Vliegenthart, y Walgrave, 2012).

Autores como Atton (2003); Candón (2010); Shirky (2011); Cammaerts, Mattoni y McCurdy (2013); Natal y Perera (2014); Carty (2015), entre otros, han visto como Internet ha sido una herramienta de suma importancia para el nacimiento y desarrollo de los movimientos de este siglo, al utilizar a este medio como una herramienta de automediación, la cual también ha permitido la expansión tanto del repertorio de acción colectiva ${ }^{1}$ (Natal y Perera, 2014), como de las lógicas de las acciones de contención (Cammaerts, 2012), principalmente en lo que se refiere a las oportunidades estructurales de mediación, es decir, oportunidades estructurales de los medios, oportunidades estructurales discursivas y las oportunidades de estructuras en red (Cammaerts, 2012).

A partir de lo expuesto es como toman mayor relevancia los conceptos de mediación y apropiación tecnológica en el estudio y entendimiento de los MS de este siglo y podrían explicar los niveles de resonancia de los MAC en las audiencias de los MS y grupos contenciosos.

Así, se parte de la idea de que en el centro de los procesos de mediación se encuentra el poder, el cual va más allá de la representación y lo simbólico: la mediación imbrica tanto a los medios de comunicación, como a los objetos materiales, la tecnología, la vida cotidiana, lo simbólico y lo discursivo, por lo cual la mediación se vuelve un concepto útil para estudiar cómo impactan las redes y la tecnología en las prácticas mediáticas y comunicativas de la vida cotidiana y en particular de los MS, a partir de procesos de negociación los cuales pueden tener variados resultados como el rechazo, la apropiación o la adopción de dichas tecnologías y prácticas comunicativas (Hepburn, 2013).

Desde este punto de vista, la mediación ${ }^{2}$ permite "la aparición de nuevas aplicaciones y usos imprevistos, desde los cuales, para los activistas amplía las posibilidades de resistencia al

\footnotetext{
${ }^{1}$ Tilly (1998 y 2006) define a los repertorios de acción como el conjunto de medios de los que dispone un grupo para perseguir objetivos en común y los entiende como la totalidad de herramientas colectivas, aprendidas y compartidas, que se utilizan deliberadamente para conseguir uno o varios objetivos en común y que están delimitadas estructuralmente y construidas culturalmente.

${ }^{2}$ El español Martin-Barbero (1991) fue de los primeros estudiosos de la comunicación que introdujo el concepto de mediaciones, con ello cambió el objeto de estudio al dejar el análisis de los medios, para volcarse a las mediaciones a partir de las cuales las audiencias decodifican los contenidos mediáticos, es decir, los "lugares" en donde se produce el sentido de los usos, con diferentes temporalidades y matrices culturales. Lugares en los cuales la comunicación se vuelve un espacio estratégico de lucha y desde donde se llevan a cabo las transformaciones en las culturas subalternas.
} 
Perera Ramos, R. (2019)

Comunicación y acción colectiva. Estudio de caso de la resonancia en estudiantes universitarios de los marcos movilizadores de Anonymous

pp. $75 / 107$

extender la variedad de posibles prácticas de los medios y el repertorio de la acción contenciosa” (Hepburn, 2013: 4).

La mediación y la apropiación de las TIC es sustancialmente importante ya que a partir de la comunicación es desde donde se produce y se apropia el significado dentro de un sistema de producción mediado simbólicamente, como todo acto social, y el cual implica el reconocimiento recíproco de la identidad, por lo que los conflictos se manifiestan en el plano cultural, al cuestionar los códigos dominantes de las sociedades complejas y al centrarse en la identidad, el espacio de vida y el tiempo (Melucci, 1996 y 2001).

Por tanto, la pugna por la producción y reapropiación del significado se vuelve la principal fuente de conflicto, es decir, el control de los códigos que permiten la comunicación en la sociedad se ha convertido en el principal objeto de lucha y un recurso vital del control social, ya que los desafíos se hacen presentes con una inversión de los códigos culturales, donde los signos se vuelven intercambiables y "el poder se sitúa en los lenguajes y en los códigos que organizan el flujo de información”, por lo que la producción y subversión de los códigos culturales constituye la principal actividad de los movimientos y una condición necesaria para la visibilidad de la acción (Melucci, 2001: 28).

Como consecuencia, los procesos de automediación de las redes de acción colectiva se incrustan en la lucha por el poder simbólico, bajo el entendido de que la automediación es:

[...] el "manejo de la visibilidad" y la "lucha por el reconocimiento" que enlaza con una presencia y una voz en el mainstream mediático audio-visual e impreso, y visibilidad como movimiento u organización a través de canales independientes de comunicación (Thomson citado en Hepburn, 2013:4).

De esta forma, la mediación entendida como "el proceso social en donde los medios sostienen el flujo de discursos, significados e interpretaciones en las sociedades" (Mattoni y Treré, 2014:260), no puede ser desligada de la apropiación de las TIC ya que

[...] la mediación, también implica la reconfiguración de las tecnologías de los medios de comunicación y las remediaciones de los significados de los medios. A través de la reconfiguración, los activistas se apropian y adaptan las tecnologías de los medios para sus propios propósitos, mientras que mediante la remedición los actores de los movimientos sociales crean nuevos significados, empezando por las obras culturales ya existentes y los productos de los medios" (Mattoni y Treré, 2014: 260).

En síntesis, dentro de los procesos de mediación y apropiación existen prácticas diarias en las cuales los actores sociales actúan con resistencia y resiliencia hacia la dominación y la hegemonía, al producir e intercambiar múltiples significados. 
Por tanto, la comunicación automediada se convierte en un fin y en un medio para los MS, como fin los sistemas de acción intentan intervenir en los procesos de la construcción del sentido, como medio "ofrecen al resto de la sociedad otros códigos simbólicos que subvierten la lógica de aquellos que dominan en ella”, sacando a la luz "lo que el sistema no dice de sí mismo, la cuota de silencio, la violencia, la arbitrariedad que siempre subyace en los códigos dominantes” (Melucci, 1999: 126).

\section{Marcos de acción colectiva y resonancia}

Autores como Cammaerts (2012) y Mattoni y Treré (2014), entre otros, han propuesto que los procesos de automediación, a través de las TIC (en particular mediante Internet), así como los de apropiación, por parte de los grupos y organizaciones de la movilización social, facilitan y permiten exponenciar las posibilidades comunicativas de estos.

Lo expuesto deviene en una mayor capacidad de estos actores colectivos en intervenir en la construcción del sentido, a partir del uso de un medio de comunicación masiva, como Internet, el cual les brinda mayores posibilidades tanto en la diseminación de sus enmarcados, como en la resonancia de estos, al ser automediados.

Lo anterior, al ser comparado con la verticalidad e inaccesibilidad de los mass media tradicionales, controlados en muchos casos por el poder político y/o económico, quienes tienden un cerco mediático a sus oponentes y grupos de resistencia (Sádaba, 2012), así como también los deslegitiman a partir de contramarcos basados en los discursos dominantes y que, por lo tanto, ostentan una mayor poder de resonancia en las audiencias, en contraste con aquellos marcos novedosos, desafiantes del discurso dominante $\mathrm{y}$ muchas veces contrahegemónicos y contraculturales ${ }^{3}$.

En efecto, aunque no es uno de los objetivos de este trabajo profundizar en las cualidades instrumentales de Internet ${ }^{4}$, es importante mencionar que este medio permite tener una comunicación horizontal, mediante un mismo canal de comunicación, con mayores posibilidades de interacción, dentro de plataformas multimedia y desancladas temporal y espacialmente a partir de la recombinación de tres modelos de comunicación: uno-a-muchos, muchos-a-muchos y muchos-a-uno (Candón, 2010).

A su vez, Internet se presenta como un medio menos jerarquizado y más abierto para que cualquier usuario pueda publicar contenidos propios sin ser objeto de censura (con sus bemoles y matices), a costos muy bajos o prácticamente nulos, lo que le da mayor accesibilidad, en comparación con los medios de comunicación masiva tradicionales (Candón, 2010).

\footnotetext{
${ }^{3}$ Los MS como constructores de sentido están en una constante tensión con los mass media, ya que como concluye Van Dijk (1988), en los discursos sobre problemas de corte social, es la interpretación de los dominantes la que más atención recibe por parte de los medios.

${ }^{4}$ Para mayor profundidad en el tema véase Candón (2010).
} 
Perera Ramos, R. (2019)

Comunicación y acción colectiva. Estudio de caso de la resonancia en estudiantes universitarios de los marcos movilizadores de Anonymous

pp. $75 / 107$

En suma, las cualidades descritas convierten al ciberespacio como un medio y lugar idóneo para la diseminación y construcción de marcos desafiantes a los códigos dominantes, por lo que Internet puede ser visto como una caja de resonancia ad hoc para los procesos de creación y diseminación de los MAC.

En cuanto a los marcos de referencia de la acción colectiva, estos son conceptualizados como esquemas interpretativos que simplifican y condensan (empaquetan) el mundo exterior "al señalar y codificar selectivamente a los objetos, situaciones, acontecimientos, experiencias y las acciones que se han producido en el entorno presente o pasado de cada individuo" (Hunt, Benford y Snow, 1994: 228).

Por su parte, los procesos de creación de los MAC pueden ser entendidos como aquellos en los que se establecen las conexiones ideológicas entre individuos y grupos, así como a través de los cuales se proponen, refuerzan y adornan las identidades colectivas (Hunt, Benford y Snow, 1994).

Asimismo, la creación de los MAC es un proceso constante ${ }^{5}$ en el que se pueden distinguir tres campos de identidad: los protagonistas, los antagonistas y las audiencias.

Los protagonistas son los que promueven o simpatizan con los valores, metas y prácticas de un MS, así como los beneficiados directamente de las acciones del movimiento; los antagonistas son quienes parecen estar unidos para oponerse a los esfuerzos de los protagonistas y las audiencias son entendidas como aquellos que son neutrales o son observadores no comprometidos, aunque algunos de ellos puedan responder a, o informar de, los acontecimientos que presencien.

Estos tres campos de identidad, al ser parte del enmarcado de los MS, no permanecen constantes, es decir, son elásticos y se solapan entre sí (Hunt, Benford y Snow, 1994).

La construcción de los MAC son procesos en los que se atribuyen significados e interpretaciones sobre el mundo de la vida, que delimitan a un movimiento y sus actividades en el espacio y en el tiempo (Hunt, Benford y Snow, 1994) y cumplen tres funciones principalmente: al interior cohesionan y mantienen a la identidad colectiva; al exterior permiten el reconocimiento tanto de su identidad, como de lo que promueve y defiende el actor colectivo; en tercer lugar, a través de los marcos y sus alineamientos posibilitan crear nuevas simpatías, adherentes y lazos de solidaridad entre sus audiencias, lo que les confiere cierto grado de legitimidad.

El enmarcado de los MS es el que posibilita la acción colectiva, a partir de interpretaciones intersubjetivas de la realidad, al dotar de sentido a la acción a través de la elaboración de tres constructos: 1. el diagnóstico de una situación o problema que es intolerable y debe ser

\footnotetext{
${ }^{5}$ Los procesos de creación de los MAC son vistos por los estudiosos del tema como un proceso constante debido a que los MAC son dinámicos, se encuentran en constante cambio a partir de las interacciones de la identidad colectiva con su medio ambiente y a su interior.
} 
Perera Ramos, R. (2019)

Comunicación y acción colectiva. Estudio de caso de la resonancia en estudiantes universitarios de los marcos movilizadores de Anonymous

pp. $75 / 107$

transformada y en la que se atribuye una responsabilidad o culpabilidad a esta situación enmarcada; 2. un pronóstico en el qe se enmarca la solución al problema, las metas u objetivos, así como los medios para alcanzarlos (tácticas y estrategias) y; 3 . un marco de motivación, esto es, un llamamiento a las armas en donde se construyen los motivos fundamentales para entrar en acción.

Por último, Gamson en Chihu (2006: 222) propone tres componentes analíticos para el estudio de los marcos de acción colectiva, estos son:

1. Injusticia: un 'marco' debe ser capaz de transmitir indignación moral. En este sentido, los actores deben estar motivados para reconocer que la situación a la cual se dirige la movilización es dañina y produce sufrimiento. La interpretación en este caso, no es puramente intelectual, sino que involucra también los sentimientos. 2. Agencia: un "marco" debe despertar la conciencia en los miembros del movimiento, y hacerles sentir que son capaces de alterar las condiciones o las políticas mediante la acción colectiva. El "marco" debe causar en los actores la sensación de ser agentes de su propia historia. 3. Identidad: un "marco" debe ayudar a los actores a construir un "nosotros", con referencia a un "otro" antagónico. La identidad de un movimiento social requiere necesariamente la presencia de un adversario.

\subsection{Resonancia y audiencias de los MS}

En la teoría de los MAC el concepto de las audiencias es poco atendido y concebido como si fuera una lista de supermercado al ser definido como un campo integrado "por las organizaciones afines al movimiento, los medios de comunicación, las élites del poder, los seguidores marginales, los simpatizantes y la gente de la calle” (Hunt, Benford y Snow, 1994: 240) y, a su vez, es acotado este campo de identidad tan sólo al considerar una caracteriza común en ellas, esto es, aquellas "capaces de recibir favorablemente los mensajes de los protagonistas” (Hunt, Benford y Snow, 1994: 240).

Sin embargo, a pesar de esta poca atención teórica y conceptual, los autores de esta teoría señalan la trascendencia de las audiencias en los procesos de enmarcado y en el desarrollo de los MS. Por tanto, en la teoría de los MAC:

[...] el proceso de identificación de audiencias es especialmente importante porque los actores de estas organizaciones activistas emplean estos marcos para determinar qué otros tipos de marcos pueden tener resonancia, qué clase de $<<$ evidencia $>>$ hay que presentar para apoyar las demandas del movimiento y de qué forma se pueden usar los símbolos culturales de las audiencias para impulsar esas demandas [...] Las identidades que se atribuyen a la audiencia influyen en el desarrollo de las estrategias y tácticas del movimiento (Hunt, Benford y Snow, 1994: 241).

Blee y McDowell (2012: 3) hacen una crítica hacia la poca atención que han recibido las audiencias de los MS, al argumentar que se conoce "mucho acerca de cómo los movimientos sociales enmarcan los mensajes hacia sus audiencias, pero mucho menos de cómo identifican 
Perera Ramos, R. (2019)

Comunicación y acción colectiva. Estudio de caso de la resonancia en estudiantes universitarios de los marcos movilizadores de Anonymous

pp. $75 / 107$

y definen la audiencia o qué consideran acerca de una audiencia cuando enmarcan sus mensajes".

De esta forma, sin pretender hacer una discusión profunda sobre el vacío conceptual descrito (dado que no es objeto de este artículo), se puede entender que las audiencias de los MS son constructos de los grupos de activistas (Blee y McDowell, 2012), es decir, son audiencias imaginadas (Marwick y boyd, 2010) y estas no pueden ser entendidas como un campo de identidad o constructo estable de los marcos de acción colectiva, dado el dinamismo de dichos marcos.

Las audiencias no son identidades estables que se congregan alrededor de un objeto, sino que son comunidades interpretativas, las cuales participan activamente en los procesos de construcción del sentido, pertenecientes a y constructoras de subculturas y subgrupos, a partir de redes interpretativas (White, 1997) y, por tanto, son agentes interpretativos y culturales que poseen estrategias comunes de comprensión de los medios y de otras formas de cultura (Jensen, 1991).

En suma, las audiencias son activas, las cuales a partir de sus diversas mediaciones interpretan y construyen variados significados sobre los múltiples eventos comunicativos en los que interactúan y estos procesos pueden conducir hacia "la afirmación de la identidad y a la proyección de esa identidad hacia movimientos para el cambio político y social" (White, 1997: 29).

En consecuencia, los grupos de resistencia buscan enfatizar en esos procesos de deconstrucción y construcción del significado en sus audiencias, al proveerlas de marcos resonantes, los cuales permitan conducirlas hacia la acción social. Lo anterior significa que los MS construyen/imaginan a sus audiencias pensando en la acción.

Las organizaciones contenciosas desean audiencias activas y no sólo durante las demostraciones públicas, sino también más allá de los actos performativos. "Los activistas tratan de remodelar las orientaciones cognitivas de sus audiencias hacia la acción, empujándolos desde la rutina automática hacia la acción deliberativa (reflexiva)” (Blee y McDowell, 2012: 3).

Sin embargo, la relación entre la identidad colectiva y sus audiencias es dialéctica, esto quiere decir que los grupos subversivos construyen sus marcos de acción a partir del constructo que hacen de sus audiencias, así como a partir de las interacciones con estas, por lo que alinean sus marcos con el fin de obtener una mayor capacidad resonante y de esta forma conseguir un mayor número de adherentes, lazos de solidaridad y evocar simpatía y afectividad hacia el movimiento.

Lo anterior conduce a pensar, como lo señalan Snow y Benford (2006), en que los MS son agencias de significación y, por tanto, involucrados, juntos con los medios masivos de comunicación y el Estado, en la política de la significación (Hall, 1982) y en la construcción de la cultura. 
Perera Ramos, R. (2019)

Comunicación y acción colectiva. Estudio de caso de la resonancia en estudiantes universitarios de los marcos movilizadores de Anonymous

pp. $75 / 107$

De este modo, los grupos de resistencia intentan movilizar a sus simpatizantes y reclutas potenciales, así como ganar el apoyo de los espectadores y desmovilizar a sus antagonistas, a través de la creación de marcos resonantes, es decir, marcos que exploten y amplifiquen, de forma imaginativa e inspiradora, las experiencias y situaciones presentes en el mundo de la vida de los adherentes potenciales, lo que les permite superar la galvanización social y conducirlos hacia la acción (Snow, Rochford, Worden y Benford, 2006).

Por tanto, se pude decir que, en buena medida, el grado de resonancia de los marcos determina el éxito de un enmarcado movilizador y este depende de los procesos de alineamiento del marco para tener una mayor o menor resonancia (Snow, Rochford, Worden y Benford, 2006).

En este sentido, se entiende que en la creación de los MAC están involucrados procesos en los que se construyen puentes articuladores entre las orientaciones de los individuos atomizados y las orientaciones interpretativas de los grupos reivindicativos de tal modo que un conjunto de intereses, valores y convicciones de los individuos sean congruentes y complementarios con las actividades, metas e ideología de la identidad colectiva (Snow, Rochford, Worden y Benford, 2006), lo que permite sobrepasar las restricciones de los marcos, en cuanto a su capacidad de resonancia, tanto en las dimensiones infraestructurales de los sistemas de creencia ${ }^{6}$, como en las fenomenológicas ${ }^{7}$, a partir de "los distintos procesos interactivos y de comunicación que influyen en el alineamiento de marcos” (Snow, Rochford, Worden y Benford, 2006: 33).

En síntesis, la breve exposición teórica-conceptual de estos apartados da cuenta, desde una visión fenomenológica, de la importancia de la comunicación de los MS y de sus audiencias en los procesos de construcción de los MAC y el éxito de estos en pos de generar lazos vinculantes orientados a la acción social. A su vez, permite inferir, desde un enfoque comunicológico, las posibilidades que ofrece un medio como Internet al ser apropiado por los MS como una herramienta de automediación entre los grupos y organizaciones de activistas y sus audiencias con el fin de generar y diseminar marcos con mayor resonancia, lo cual podría potencializar sus capacidades de reclutamiento y de generación de lazos de solidaridad con las causas que defienden, así como orientar a sus audiencias hacía la acción social.

\footnotetext{
${ }^{6}$ Las restricciones infraestructurales del marco de acción colectiva son las que se refieren, en general, a la estructura interna de la ideología o del sistema general de creencias, el cual observa tres componentes centrales: "1. la centralidad o importancia jerárquica de algún elemento ideológico particular en relación con otros elementos semejantes dentro de la totalidad del sistema de creencias; 2. el alcance de los elementos ideológicos centrales, es decir, los dominios vitales que abrace; y 3. el grado de cohesión existente entre los diferentes elementos del sistema de creencias” (Snow y Benford, 2006: 98).

${ }^{7}$ Las restricciones fenomenológicas se relacionan "con el grado en que el trabajo de enmarcado resulta resonante para el mundo de vida de los participantes potenciales” (Snow y Benford, 2006: 98). Estas restricciones tienen que ver con la pertinencia del enmarcado en cuanto a su: 1 . Credibilidad empírica; 2. La afinidad de la experiencia personal; y 3. La fidelidad narrativa.
} 
Perera Ramos, R. (2019)

Comunicación y acción colectiva. Estudio de caso de la resonancia en estudiantes universitarios de los marcos movilizadores de Anonymous

pp. $75 / 107$

Por su parte, desde el punto de vista de las audiencias, también es importante tomar en cuenta que las lecturas que hacen estas del enmarcado de la acción colectiva (y por ende el grado de resonancia de los marcos) dependerá sustancialmente de sus diversas mediaciones, entre ellas sus niveles de apropiación de las TIC.

Las siguientes páginas tienen como propósito analizar de manera empírica, a través de un estudio de caso y mediante el andamiaje teórico y conceptual expuesto, el grado de resonancia de los MAC de Anonymous en estudiantes universitarios y las mediaciones que intervienen en estos procesos comunicativos.

\section{Metodología}

La estrategia metodológica de esta investigación está basada en un estudio de caso simple, ya que presenta solamente el análisis de un colectivo de resistencia social (Anonymous) y un segmento de la población específico o audiencias (estudiantes de licenciatura de la Universidad Nacional Autónoma de México [UNAM]). Las audiencias fueron delimitadas al campus más representativo y más grande de la UNAM, esto es, Ciudad Universitaria (CU). Igualmente, el análisis sólo abarca a los estudiantes de licenciatura que cursan sus estudios en el sistema escolarizado de la universidad.

Este tipo de estrategia metodológica fue seleccionada debido a que, como señala Yin (1994), los estudios de caso permiten hacer investigaciones de tipo exploratorio, descriptivas o explicativas. En este estudio la flexibilidad de este método permitió tanto describir a los MAC de Anonymous, como también estudiar las relaciones causales propuestos en la introducción de este trabajo.

Además, el método de estudio de caso posibilita utilizar una variedad de técnicas de investigación desde cualitativas (como la entrevista a profundidad o la etnografía), hasta cuantitativas (como la encuesta). De esta manera, en los estudios de caso puede utilizarse todo el abanico de técnicas de investigación, lo que le permite al investigador apoyarse en cualquier técnica de indagación, de acuerdo a sus objetivos y preguntas de investigación para recolectar los datos más pertinentes a su estudio, lo que incluye fuentes secundarias y primarias (Yin, 1994), por lo que faculta el uso de técnicas de investigación mixtas, como el realizado en esta pesquisa.

A su vez, el método de estudio de caso simple es uno de los más adecuados para investigaciones que abordan fenómenos sociales contemporáneos y en donde el investigador tiene poco control sobre los eventos (como lo es el objeto de estudio de esta investigación) y es idóneo para contrastar los resultados empíricos con teorías, supuestos o hipótesis prexistentes y, a partir de ello, generar nueva teoría, rectificarla o verificarla (Yin, 1994).

La elección de realizar un estudio de caso simple, en lugar de un estudio de caso múltiple, se debe a que el estudio de caso simple pude usarse para determinar si las proposiciones de una teoría son correctas o si algún conjunto de explicaciones es más pertinente, ya que se 
Perera Ramos, R. (2019)

Comunicación y acción colectiva. Estudio de caso de la resonancia en estudiantes universitarios de los marcos movilizadores de Anonymous

pp. $75 / 107$

considera a este tipo de estudios de caso como un análogo de la experimentación simple (Yin, 1994).

Siguiendo a Yin (1994), la razón por la que se puede emplear el caso simple es cuando este representa un caso crítico para la teoría preexistente, de tal modo que puedan probarse las proposiciones teóricas (las cuales se asumen como verdaderas) mediante un caso idóneo, es decir, mediante un caso en donde se encuentren todas las condiciones para probar la teoría.

La idoneidad del caso está dada a partir de la selección de un grupo crítico o significativo en donde se considera que se pueden encontrar todas las condiciones para que la hipótesis y los supuestos teóricos expuestos sean validados. Por tal motivo se escogió a Anonymous como un agente de la movilización social ideal, debido a que ha sido uno de los referentes más importantes de la acción colectiva digital (Coleman, 2016) y, a su vez, su comunicación ha sido preponderantemente automediada por Internet, por lo que lo convierte en una identidad colectiva arquetípica para el estudio y objetivos que se persiguen en este trabajo.

Los estudiantes universitarios fueron seleccionados como la audiencia idónea de Anonymous ya que es el grupo con mayor acceso a Internet en México (INEGI, 2018) y a partir de la idea de que, dada su edad y nivel de estudios, presentan un grado mayor de apropiación de las TIC, en comparación con otros sectores de la población mexicana, como ya ha sido demostrado en investigaciones previas (p.ej. Crovi 2016, 2017 y 2018).

Sin embargo, el criterio de mayor peso para escoger a los estudiantes universitarios, como el universo de estudio ideal, fue dado a partir de los hallazgos del análisis del discurso (correspondiente a una primera etapa de esta investigación), en el cual se encontró que Anonymous se dirige, especialmente, a este grupo de la población.

Por su parte, se eligieron a los alumnos de la UNAM debido a que esta universidad es masiva y es una de las universidades más importantes y con mayor población de Iberoamérica; además es pública y gratuita por lo que su alumnado presenta una alta diversidad en cuanto a su estrato social.

A su vez, la apertura ideológica con la que cuenta la universidad y el historial de sus alumnos, como protagonistas del movimiento estudiantil mexicano, contribuyeron para que su comunidad de estudiantes fuera pensada como una audiencia idónea de Anonymous.

En lo que se refiere a las técnicas de recolección de datos utilizadas, estas fueron tanto cualitativas (observación indirecta y análisis del discurso), como cuantitativas (levantamiento de encuesta y análisis estadísticos), por lo que la indagación empírica está sustentada en una metodología mixta de dos pasos ${ }^{8}$.

\footnotetext{
${ }^{8}$ El método mixto, también denominado enfoque integrado multimodal, es definido por el uso de los dos métodos (cualitativo y cuantitativo) en un mismo estudio y es un método mixto en dos etapas, ya que se aplica primero el método cualitativo (para estudiar el marco de acción colectivo de Anonymous) y, posteriormente, el método cuantitativo (para medir la resonancia del marco de acción colectivo mediada por Internet en las
} 
Perera Ramos, R. (2019)

Comunicación y acción colectiva. Estudio de caso de la resonancia en estudiantes universitarios de los marcos movilizadores de Anonymous

pp. $75 / 107$

La primera fase de esta pesquisa se enfocó hacia la indagación del MAC de Anonymous, a través de la técnica de observación indirecta ${ }^{9}$, mediante fuentes secundarias, esto es, una investigación documental sobre este actor colectivo, en la cual destacan las pesquisas realizadas previamente por Knappenberger (2012), Olson (2013), Hai-Jew (2013), Coleman (2016) y Asenbaum (2017).

Los estudios citados sirvieron, principalmente, para contextualizar al grupo hacktivista Anonymous, aunque también se recurrió a otras fuentes indirectas con el fin de tener un panorama más amplio sobre la escena y subcultura hacker, en la que está insertado Anonymous y el movimiento del software libre (p.ej. Levy, 1994; Castells, 2001; Ludlow, 2001; Samuel, 2004; Friedman, 2005 y Ariño, 2009, entre otros).

Posteriormente, a partir de la observación indirecta, se realizó un análisis del discurso de Anonymous mediante un corpus compuesto por catorce videos publicados por el grupo de hacktivistas en su canal oficial de You Tube (Anonymous Official ${ }^{10}$ ). Estos videos fueron difundidos en ese espacio de entre el 15 de marzo de 2105 y el 17 de julio de 2107. La selección del corpus se hizo con base en la información sobre el enmarcado del colectivo, ofrecida en cada uno de los vídeos elegidos.

Las categorías analíticas utilizadas para el estudio del discurso fueron retomadas de la teoría de los MAC y estas son: marco de injusticia-diagnóstico de la situación, marco de identidad (definición de un yo en contraste del o los antagonistas) y marco de agencia, es decir, pronóstico y llamado a la acción colectiva, en el que se incluyeron los objetivos, estrategia, tácticas y medios para la acción.

Dentro de las categorías analíticas mencionadas se agregó al campo de identidad de las audiencias de Anonymous, a través de analizar hacia quién está orientada la comunicación del colectivo, por lo que se complementaron los tres campos de identidad propuestos en el modelo teórico (protagonistas, antagonistas y audiencias) de los MAC.

El análisis del discurso contempló seis dimensiones analíticas: contexto, estrategia discursiva, significado, forma y acción. Estas seis dimensiones, así como las categorías fueron estudiadas en su semántica global y/o local, según fuera pertinentes para los objetivos de la investigación.

Cabe señalar que, el modelo que se construyó para este estudio hace mayor énfasis en la interpretación, en comparación con el análisis formal (lingüístico-semiótico) y se adhiere

audiencias). Estas etapas son relativamente independientes y se respetan los métodos inherentes a cada enfoque (Hernández, Fernández-Collado y Baptista, 2003).

${ }^{9}$ La observación indirecta es definida como el análisis de datos a partir de fuentes secundarias, por lo que el investigador entra en conocimiento del hecho o fenómeno observado a través de las observaciones realizadas anteriormente por otra persona y en las que se vale de libros y artículos científicos, entre otro tipo de fuentes (Díaz, 2011 y Saens y Tamez, 2014).

${ }^{10}$ https://www.youtube.com/channel/UCA071Pllf2wk-B8Rkwt47bQ 
Perera Ramos, R. (2019)

Comunicación y acción colectiva. Estudio de caso de la resonancia en estudiantes universitarios de los marcos movilizadores de Anonymous

pp. $75 / 107$

hacia la corriente del Análisis Crítico del Discurso y tomó como base el triángulo analítico propuestos por van Dijk (2003) ${ }^{11}$.

En general, el modelo para el análisis del discurso, de esta investigación, está sustentado en las directrices sugeridas por van Dijk (2003, 2004 y 2005) y especialmente las utilizadas por el autor para analizar las ideologías de grupos.

En la segunda etapa de la pesquisa, una vez definidos los MAC de Anonymous (a través de su discurso), el enmarcado del colectivo fue operacionalizado con la finalidad de medir su resonancia mediante la técnica de encuesta, en las audiencias seleccionadas (estudiantes de licenciatura de la UNAM, del campus CU), así como para, a partir de modelos de regresión y correlaciones, observar cuáles son las variables (mediaciones) estadísticamente más significativas que inciden en el grado de resonancia observado.

Para el análisis inferencial se crearon tres índices a partir de los datos recolectados ${ }^{12}$ : Índice de Resonancia del Marco de Acción Colectiva, Índice de Actitudes y Partición Política No Institucional e Índice de Apropiación de Internet.

${ }^{11}$ El Triángulo de van Dijk (2003), se caracteriza por poner especial énfasis en el contexto (global y local) del discurso, a partir de sus dimensiones cognitivas y sociales, las cuales lo definen (van Dijk, 2003). En general este triángulo interrelaciona tres dimensiones: cognición, sociedad y discurso. La cognición son los marcos o los esquemas mediante los cuales los individuos y grupos sociales interpretan y dan significado al discurso, pero también a través de los cuales lo construyen. A su vez, estos esquemas son compartidos por los grupos sociales, por lo que también son representaciones sociales. En términos de Van Dijk (2004: 16), los marcos o esquemas son "representaciones mentales socialmente compartidas tal como el conocimiento, las normas, los valores y las ideologías". Por tanto, la cognición es la que regula, supervisa y actúa como mediadora entre sociedad y discurso. Esta mediación explica los significados, las intenciones, funciones, comprensiones, intencionalidades, el conocimiento y muchos aspectos más del discurso. Como acción e interacción de la sociedad, la mediación cognitiva permite comprender los discursos y producirlos (Van Dijk, 1997). Sin embargo, estas representaciones mentales, actúan en contextos sociales, en la interacción social, en situaciones sociales. Los discursos están socialmente contextualizados por los participantes, es decir, existe una intersubjetividad cognitiva. Los usuarios de la lengua comparten ciertos conocimientos, actitudes, valores e ideologías, que forman modelos mentales compartidos. Estos modelos mentales reflejan las metas, los intereses, la posición social y demás dimensiones sociales de un grupo (Van Dijk, 1997). Por su parte, en y por el discurso se constituyen todas las representaciones mentales, estructuras, instituciones y relaciones sociales.

12 Todas las variables e indicadores con un nivel de medición nominal u ordinal, fueron operacionalizados, codificados y estandarizados en una escala del 0 al 5 y del -5 al 5 , según fuera el caso (p.ej. sentimientos negativos o conocimientos negativos sobre Anonymous vinculados al contramarco), de tal forma que los resultados pueden arrojar índices con números negativos. En general, el modelo metodológico cuantitativo que se elaboró se circunscribe al de los estudios de medición de actitudes, utilizado principalmente en la psicología y en la comunicación política. Por ende, todos los indicadores para su operacionalización y transformación a una un nivel de medición escalar y su conversión a índices observaron las técnicas de proporción manifiestas, las cuales suponen que los atributos a medir poseen las propiedades de razón (cero absoluto) y se utilizaron tanto los procedimientos de la Escala de Likert, como de la Escala de Guttman. 
Los tres índices construidos son complejos y sólo el Índice de Resonancia del Marco de Acción Colectiva fue elaborado al ponderar las variables e indicadores a partir de un criterio subjetivo basado en la observación indirecta y en los resultados del análisis del discurso de Anonymous (en los otros dos índices no se usó ningún tipo de ponderación).

El nivel de la resonancia del enmarcado de Anonymous (en los estudiantes) fue medido a través de tres dimensiones: cognitiva, afectiva y participativa. En cada una de estas dimensiones se observaron las tres categorías analíticas propuestas en la teoría: marco de injusticia, marco de agencia y marco de identidad, con las que se articularon 17 variables dependientes, las cuales contienen 82 indicadores.

En lo que se refiere a las variables independientes, además de estar constituidas por variables sociodemográficas (sexo, edad, nivel socioeconómico, semestre y facultad), también se crearon cuatro variables dirigidas a medir aspectos puntuales de la cultura política de los estudiantes como su interés en los asuntos públicos y políticos, su participación en movimientos o causas sociales e importancia y capacidad que le confieren los educandos a los MS en transformar a la sociedad.

Otro conjunto de variables independientes fue el destinado a medir el nivel de apropiación de los universitarios de las herramientas digitales y en particular de Internet. Para ello, dicho grado de apropiación fue medido a través de tres dimensiones: acceso, uso y simbólico, a partir de 13 variables constituidas por 80 indicadores.

En total el cuestionario abarcó 40 preguntas cerradas y dos abiertas y la técnica de su aplicación fue cara a cara, a partir de un muestreo aleatorio por cuotas. Las cuotas se establecieron desde los datos sociodemográficos publicados por la propia universidad, por lo que se otorgó un peso proporcional a cada facultad, escuela o centro de estudios del campus y dentro de estos su proporción relativa por sexos.

El universo de estudio comprendió a 89,706 estudiantes y de los cuales fueron muestreados 442 de ellos ${ }^{13}$, lo que dio como resultado un margen de error no mayor a 0.05 con un nivel de confianza de $95 \%$.

Por último, la encuesta fue aplicada los días 19, 20 y 21 de septiembre de 2018 y se levantaron previamente dos pruebas piloto. Asimismo, los resultados de dicha encuesta fueron analizados a la luz de los hallazgos de la primera etapa cualitativa de la investigación.

\section{Anonymous}

Aunque no es el objetivo de este artículo describir a Anonymous y su enmarcado, ya que el espacio no sería suficiente y se le quiso dar prioridad a los resultados de la resonancia en sus

\footnotetext{
${ }^{13}$ De manera general el perfil sociodemográfico de la muestra está constituido de la siguiente forma: $51 \%$ de los cuestionarios fueron aplicados a mujeres, la edad preponderante de los encuestados se encuentra entre los 19 y 21 años (54\%) y la mayoría de los estudiantes seleccionados observan un estrato socioeconómico medio (49\%), seguidos de un nivel medio-bajo (32\%).
} 
Perera Ramos, R. (2019)

Comunicación y acción colectiva. Estudio de caso de la resonancia en estudiantes universitarios de los marcos movilizadores de Anonymous

pp. $75 / 107$

audiencias y las mediaciones que pudieran explicarla, es necesario dar una breve descripción de este grupo hacktivista y sus MAC.Anonymous empezó a forjar su identidad colectiva desde el año 2003 en el canal/b/ de 4Chan. La plataforma de 4Chan es un tablero de imágenes del ciberespacio, el cual se ha distinguido por su apertura, nula censura y por respetar el anonimato de sus usuarios.

4Chan y en particular el canal de /b/ (canal de tipo random o sin tema específico) es caracterizado por lo grotesco y la aparente anarquía de sus contenidos e interacciones, así como por ser un lugar en donde el troleo ${ }^{14}$ es parte importante de la subcultura de sus usuarios.

De manera amplia se puede entender que, en 2003, 4Chan (y de forma específica el canal /b/) constituía un espacio oculto dentro de Internet, el cual estaba basado en los valores de la ética hacker como la horizontalidad, anonimato, meritocracia, creatividad, experimentación y libre flujo de la información ${ }^{15}$.

En síntesis, el subtablero de imágenes /b/, basado en un humor muy particular de la subcultura hacker (Torres, 2013), era una "celebración carnavalesca a la libertad de expresión, a través de la transgresión de las convenciones y los tabús” (Ausenbuam, 2017:1516).

De esta forma, el subtablero /b/ de 4Chan se convirtió en un refugio de los herederos de la subcultura hacker, especialmente para los subterráneos de dicha subcultura, es decir, cyberpunks, script kiddies y crackers, que con el tiempo construyeron la identidad colectiva Anonymous, conformando así una comunidad en línea de hacktivistas.

La identidad Anonymous empezó a solidificarse en 2004, cuando tuvieron que actuar colectivamente para defender las políticas de anonimato de 4Chan ante otros miembros de la comunidad de esa plataforma, quienes no deseaban que el anonimato fuera una regla obligatoria. Los usuarios que no favorecían el anonimato empezaron a escribir en tripcodes ${ }^{16}$, para poder identificarse, y se burlaban de los usuarios anónimos tratándolos como si fueran una misma persona llamada Anonymous y se referían a ellos como una mente colmena o de enjambre.

Con el tiempo la burla se desvaneció, pero el sentimiento de una identidad colectiva llamada Anonymous prevaleció (Olson, 2012) y se convirtió en una tradición, dentro de la comunidad

\footnotetext{
${ }^{14}$ Coleman (2012) considera al fenómeno del trol como una subcultura novedosa, con normas culturales y códigos lingüísticos propios. A su vez, "los troles tienen una predisposición especial para atacar a personas que muestran un desconocimiento evidente de las reglas del ciberespacio o a las que se creen seguras en sus posiciones de poder [...] el trolling expresa una forma específica de humor negro y sarcasmo, de provocación y de perversión, que sus miembros denominan lulz (bastardización de laughing out loud)” Pecourt, 2016: 142). Con frecuencia los troles suelen tener conocimientos básicos de hackeo.

${ }^{15}$ Para un mayor acercamiento hacia la ética hacker véase Levy (2004).

${ }^{16}$ Un tripcode es el resultado de una contraseña codificada, la cual permite que una identidad sea reconocida sin almacenar ningún dato sobre el usuario.
} 
Perera Ramos, R. (2019)

Comunicación y acción colectiva. Estudio de caso de la resonancia en estudiantes universitarios de los marcos movilizadores de Anonymous

pp. $75 / 107$

4Chan, asegurar que Anonymous era una misma persona. "Esta tradición convirtió a Anonymous en una palabra clave, una identidad compartida y también en un saludo secreto" (Battocchio, 2014: 27).

Durante los años siguientes la identidad colectiva se fue afirmando a través de acciones colectivas meramente lúdicas (como el troleo) o combinando lo lúdico con lo político. De este último tipo de operaciones (como llama Anonymous a sus acciones colectivas) destacan las protestas dentro de los juegos en línea Habbo Hotel y World of Warcraft, en 2006, como acto de resistencia contra el racismo y la discriminación; la campaña contra el locutor de radio Hal Turner, durante 2006 y 2007, debido a sus comentarios racistas y xenofóbicos; y la localización y doxeo ${ }^{17}$ (en el año de 2007) del pedófilo canadiense Chris Forcand, quien atraía a menores de edad a través de Internet.

En suma, bajo la identidad colectiva de Anonymous sus miembros empezaron a colaborar en proyectos colectivos reivindicativos asociados a los valores y principios que persigue la cultura de Internet y, de forma particular, en aquellos relacionados con la subcultura hacker. Dentro de estos últimos sobresale el anonimato (asociado con la horizontalidad, equidad y la anticelebridad) y la libertad de expresión enmarcada desde la concepción hacker, esto es, privacidad, anticensura, libre flujo de las ideas y del conocimiento y derecho a ser escuchado.

De esta forma para 2008 Anonymous ya se había autoproclamado (de la misma forma que ya lo había hecho con anterioridad la comunidad de hackers) como guardianes y defensores de Internet y reivindicó ese espacio como suyo.

El punto de inflexión, en el cual se puede decir que empezó la fase de visibilidad de este colectivo de hacktivistas, fue en 2008 a partir de las acciones colectivas que desarrollaron masivamente, por casi un año, contra la Iglesia de Cienciología y en defensa de las libertades en Internet, las cuales, desde el punto de vista del colectivo, fueron violentadas al tratar la secta de censurar y aplicar los derechos de autor a un video propagandístico de la iglesia, que había sido filtrado para su publicación en el ciberespacio por un detractor de la iglesia.

Bajo el agravio mencionado, Anonymous lanzó una cruzada contra la Iglesia de Cienciología en enero de 2008, en la cual, a diferencia de las operaciones anteriores, el colectivo se abrió a toda la comunidad de Internet buscando su apoyo para que se adhirieran grupos más amplios a sus acciones.

Lo anterior condujo a un alineamiento importante de los MAC de Anonymous, a partir de las nuevas identidades y actores que se fueron sumando a su causa a nivel global y que ya no provenían de la subcultura hacker con marcos ligados a ese movimiento y a los valores ciberlibertarios, sino que eran activistas más cercanos a la Nueva Izquierda, es decir, con un modelo mental heredado de los movimientos contraculturales y sociolibertarios de las

${ }^{17}$ El doxeo consiste en vincular un perfil o identidad en línea con la identidad individual fuera de línea, al hacer pública la información privada de la víctima, como nombre real, teléfono, dirección, números de tarjetas de crédito y cuentas bancarias, huella digital, etc. 
Perera Ramos, R. (2019)

Comunicación y acción colectiva. Estudio de caso de la resonancia en estudiantes universitarios de los marcos movilizadores de Anonymous

pp. $75 / 107$

décadas de 1960 y 1970, con los cuales si bien compartían algunos valores (p.ej. libertad de expresión), la jerarquía de estos y las particularidades de la subcultura hacker (p.ej. troleo, acciones de hackeo) no eran del todo coincidentes.

La fusión de diferentes corrientes de activismo en Anonymous condujo a una ampliación de sus marcos de acción, lo que incluyó a su repertorio de acción, el cual se ensanchó al incorporar nuevas y viejas tácticas de protesta tanto online, como offline, así como también permitió una expansión global de la identidad colectiva, lo que revitalizó y le dio mayor visibilidad al movimiento hacker en uno de sus ciclos de protesta más espectaculares en toda su historia (Coleman, 2016).

Sin embargo, la incorporación de nuevas corrientes y modelos de pensamiento también acarreó mayores conflictos internos en torno al enmarcado de Anonymous, en particular aquellos referentes a la centralidad o importancia jerárquica de los elementos ideológicos dentro del sistema de creencias y con ello sus objetivos como identidad colectiva.

Otro punto álgido de disputa fueron las tácticas de acción vinculadas al hacktivismo y el troleo, que muchos de los nuevos integrantes no comprendían e incluso se opusieron a ellas.

A pesar de lo expuesto, la identidad Anonymous, a través de su narrativa performativa, conservó una imagen unificada, una identidad pública coherente y un discurso en el que prevaleció el enmarcado del grupo hacktivistas (aunque negociado), lo cual le permitió, por varios años más, desarrollar campañas exitosas enmarcadas sustancialmente en la lucha por la libertad de expresión y la defensa de Internet.

Las principales acciones colectivas de Anonymous se realizaron entre 2008 y 2013, dentro de estas se encuentran: Operación Venganza (PayBack), Operación Vengar a Assange (Avange Assange), Operación Túnez y su decidida participación en el Movimiento Occupy. Sin embargo, el ciclo de protesta de Anonymous empezó a debilitarse desde 2011, a raíz de un crecimiento de los conflictos internos y a partir de la fuerte represión de la que fueron objeto (en prácticamente todo el mundo) los miembros de Anonymous, principalmente el núcleo duro de los hackctivistas.

Tan solo entre 2011 y 2012 hubo más de 100 arrestos de integrantes de Anonymous alrededor de todo el mundo "desde Indonesia hasta la República Dominicana, desde Camboya hasta Estados Unidos. Estos arrestos son históricamente excepcionales, un listón muy alto en la historia del hackeo” (Coleman, 2016, capítulo 6, sección 4, párr. 8), dándoles condenas y multas ejemplares, especialmente en Estados Unidos. Por tanto, la impresionante oleada de actividades de protesta de Anonymous

[...] se vio enfrentada a campañas igualmente impresionantes llevadas a cabo por las fuerzas del orden [...] Los grupos de hackers que siempre habían asumido que había soplones asechando por todos los rincones, se volvieron incluso más paranoicos y reaccionaron reduciendo pertenencia al grupo y aumentando la seguridad en las operaciones que llevaban a cabo [...] En 2013 Anonymous parecía haberse alejado en gran medida de las actividades 
Perera Ramos, R. (2019)

Comunicación y acción colectiva. Estudio de caso de la resonancia en estudiantes universitarios de los marcos movilizadores de Anonymous

pp. $75 / 107$

relacionadas con la infiltración informática [...] El colectivo continuó actuando si bien de forma más moderada” (Coleman, 2016, Epílogo, sección 1 párrs. 2, 6 y 7).

Como consecuencia, en 2014 se observa, de forma clara, un nuevo alineamiento del enmarcado de Anonymous en el que prácticamente desparecieron las operaciones vinculadas a la utilización del repertorio de acción hacktivista y dan un vuelco hacia la concientización social a través de Internet y preponderantemente mediante videos difundidos en You Tube.

En este nuevo alineamiento la corriente ciberlibertaria o hacktivista dejó de ser la vanguardia de Anonymous (quienes regresaron a las sombras del ciberespacio) y fue ocupada por aquellos activistas más ligados a las corrientes de la Nueva Izquierda, aunque con un modelo mental más radicalizado allegado al anarquismo insurreccional.

Aunque en esta tercera fase de Anonymous se dio un realineamiento de los marcos sustantivo, a través del análisis del discurso, se halló que el enmarcado actual aún conserva rasgos profundos e importantes del enmarcado primario hacktivista.

Las diferencias más importantes que se encontraron fueron nuevamente en la jerarquización de los valores y objetivos dentro del sistema de creencias, ya que en esta fase se preponderan los valores sociolibertarios (como la ecología, la igualdad social y la democracia radical), aunque aún sigue presente la libertad de expresión como un valor importante, el cual vincula a ambas corrientes y con el que, en cierta medida, continúa la defensa de Internet, aunque en un nivel inferior. A su vez, en los MAC se encuentra prácticamente ausente el repertorio hacktivista de acción directa e incluso es censurado dentro del discurso.

De manera sintética, se halló un marco de injusticia con fuertes referentes hacia la corriente cyberpunk, en donde se plasma una visión de mundo o diagnóstico de la situación en el que el sistema actual y la humanidad en general se encuentran en franca decadencia y al borde de la extensión. Metáforas como "vivimos en un moderno sistema de esclavitud", "la mayor parte de la población está esclavizada y no lo sabe” o "las élites infligen un control mental sobre la humanidad", son recurrentes en el discurso.

La culpabilidad de la situación o antagonistas son las elites políticas y económicas, en particular los banqueros. Los políticos y el Estado, en general, son vistos desde el mismo esquema mental cyberpunk, esto es, como las marionetas de las élites económicas, las cuales han puesto a todos en un camino que se dirige hacia la completa y total destrucción.

En cuanto a los medios para cambiar la situación o pronóstico, estos son enmarcados mediante la concientización social o a través de despertar a los que todavía duermen, para convertirse en una mayoría de despiertos, quienes pacíficamente tomen el control social, político y económico y se haga un cambio radical a partir de una democracia deliberativa y construyan comunidades autónomas, sin jerarquías.

En su marco de identidad Anonymous se define como una idea poderosa y, como tal, inmortal. Sin embargo, en referencia con sus antagonistas, también se autodefine como 
Perera Ramos, R. (2019)

Comunicación y acción colectiva. Estudio de caso de la resonancia en estudiantes universitarios de los marcos movilizadores de Anonymous

pp. $75 / 107$

pacífico, igualitario, inclusivo, quien ostenta los verdaderos valores de la humanidad y representativo de la población mundial.

La fuerza y poder de Anonymous (su capacidad de agencia) radica por tanto en que, por un lado, es una idea poderosa e indestructible y, por otro, en sus números: "Anonymous somos todos y somos nadie". En contraste, sus antagonistas son descritos como una minoría que sólo tiene como poder el monopolio de la violencia y como consecuencia son débiles. El contraste entre un protagonista inclusivo, pacífico y numeroso con un antagonista minoritario, excluyente y violento es recurrente en el discurso.

Por último, aunque en la semántica global del discurso se encontró que Anonymous se dirige a un público general como los "ciudadanos del mundo", desde la semántica local del mismo se observa que sus audiencias imaginadas son jóvenes universitarios y con un cierto nivel medianamente alto de apropiación de las tecnologías digitales.

En este sentido, los juegos del lenguaje frecuentemente son hechos a partir de metáforas evocativas a este mundo tecnológico (p.ej. el sistema está corrupto, infectado de virus, no basta con resetear y empezar de nuevo, el sistema operativo debe ser cambiado por completo por un gobierno open source) y con un léxico propio de un discurso político formal y que es más próximo a personas con un nivel educativo alto (p.ej. legitimidad, monopolio de la violencia, control mental de grupo, estructuras de poder, capitalista de libre mercado, opinión pública, agenda de las élites, élites financieras, Era de la Comunicación, activismo digital, etc.), incluso pide a sus audiencias leer algunos libros especializados (p.ej. "La revolución francesa y la psicología de las revoluciones” de Le Bon). Finalmente, cabe señalar que el análisis del contexto local del discurso también coincidió con este constructo de audiencias.

\section{Resonancia y mediaciones del MAC de Anonymous ${ }^{18}$.}

No cabe duda que Anonymous, al menos en su fase hacktivista, es un referente del buen conocimiento y uso de sus oportunidades estructurales de mediación, así como del manejo de su visibilidad y de la lucha por su reconocimiento, lo cual lo enlazó con una presencia y una voz en el mainstream mediático audiovisual e impreso, a partir de canales independientes de comunicación.

En efecto, Anonymous (al menos durante todo un lustro) tuvo el poder de desencadenar con un solo twitt una cobertura mediática amplia y en las primeras planas del mainstream mediático (Coleman, 2016). La organización no sólo construyó una identidad estética atractiva tanto para medios, como para audiencias, al apropiarse y resemantizar elementos culturales, sino que también desarrolló una efectiva estrategia de comunicación, con base en el buen conocimiento que tenía sobre los medios tradicionales y digitales, lo que le permitió hacer tácticas mediáticas, a partir de su alto grado de apropiación de Internet, ad hoc tanto

${ }^{18}$ Debido a las restricciones de espacio sólo se presentan los hallazgos más importantes y generales del estudio. 
Perera Ramos, R. (2019)

Comunicación y acción colectiva. Estudio de caso de la resonancia en estudiantes universitarios de los marcos movilizadores de Anonymous

pp. $75 / 107$

para impactar a la prensa tradicional, como para conducir hacia la acción a sus audiencias, a partir de una comunicación automediada altamente resonante.

Anonymous creaba escenas irresistibles para los mass media (Hurst, 2013), ya que hacía uso de las oportunidades tecnológicamente mediadas de visibilidad e invisibilidad (Asenbaum, 2017). Su comunicación era un performance inacabado que invitaba a sus audiencias a participar en él y a tomar un rol activo al cederles a las audiencias el control de las secuencias de sus actos performativos, a partir de una narrativa abierta, lo que producía resultados inesperados, que incluso los propios creadores del acto no se imaginaban (Hurst, 2013). Anonymous introducía "al espectador de la política del espectáculo como actor político" (Barandiaran, 2003: 14).

No obstante, el alineamiento de sus marcos entre 2013 y 2014 también llevó a Anonymous hacia una nueva estrategia comunicativa mucho menos impactante, que la practicada durante su fase de visibilidad (2008-2013). Es decir, el colectivo conservó su identidad estética y de cierta forma su discurso, pero las operaciones ligadas al hacktivismo, que lo habían llevado a la cima del mainstream mediático, se desvanecieron junto con el poder simbólico que ostentaba y el núcleo duro de hackers que lo sustentaba y dirigió su activismo hacia una estrategia comunicativa basada, en esencia, en videos propagados a través de You Tube, lo que ha permitido que Anonymous sobreviva en una fase de latencia.

Por tanto, una de las preguntas cruciales de la investigación fue indagar qué tanto estaba presente Anonymous en el imaginario de los estudiantes universitarios mexicanos, quienes tenían una edad en un rango de entre 9 y 13 años, cuando comenzó el momento de visibilidad de Anonymous.

En consecuencia, la primera pregunta del cuestionario, referente a medir la resonancia de Anonymous en las audiencias analizadas, fue de tipo abierta ${ }^{19}$. En esta se les pidió a los estudiantes que dijeran con qué o con quién relacionaban una imagen que contenía la máscara representativa de Anonymous, la cual fue retomada por la organización a partir de la historieta y de la película V de Vendetta y la cual personifica a Guy Fawkes.

Los resultados obtenidos muestran una presencia medianamente alta de Anonymous en el imaginario de los estudiantes de la UNAM. Poco más de la mitad de los educandos (58\%), relacionaron la imagen con Anonymous por encima de la película o de cualquier otro ente o cosa (véase Figura 1).

Al preguntar de manera directa si conocían al colectivo, el nivel de conocimiento fue un poco mayor. En este caso $73.1 \%$ de la muestra afirmó tener conocimientos sobre Anonymous ${ }^{20}$.

\footnotetext{
${ }^{19}$ La pregunta al ser de tipo abierta permitió que un solo encuestado pudiera dar múltiples respuestas, las cuales fueron capturadas y analizadas, debido a ello los porcentajes totales suman más del $100 \%$.

${ }^{20}$ Esta variable también funcionó como variable de control, a aquellos estudiantes que afirmaron no conocer a Anonymous se les excluyó de las demás preguntas referentes a la resonancia del marco y estas tuvieron un valor igual a cero en su operacionalización para ser escaladas.
} 
Perera Ramos, R. (2019)

Comunicación y acción colectiva. Estudio de caso de la resonancia en estudiantes universitarios de los marcos movilizadores de Anonymous

pp. $75 / 107$

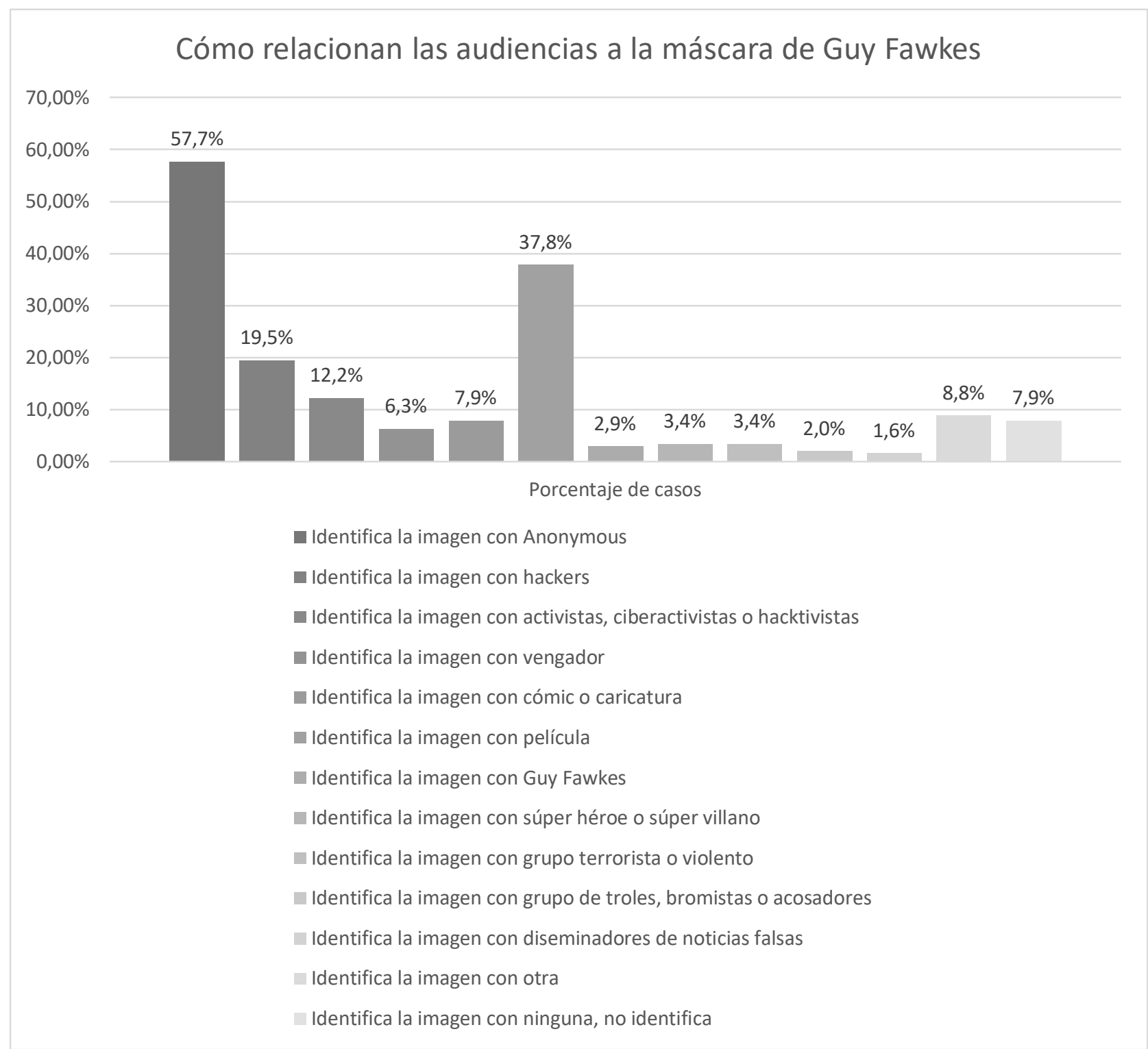

Figura 1. Cómo relacionan los estudiantes de la UNAM-CU a la máscara de Guy Fawkes. De elaboración propia.

En general, el conocimiento que tiene la población estudiada sobre la identidad de Anonymous es medianamente alto. Sin embargo, conoce menos sobre las particularidades del colectivo, por lo que al introducir variables más específicas el nivel de conocimiento decrece. 
Perera Ramos, R. (2019)

Comunicación y acción colectiva. Estudio de caso de la resonancia en estudiantes universitarios de los marcos movilizadores de Anonymous

pp. $75 / 107$

Por ejemplo, tan sólo 68\% de los que afirman conocer a Anonymous pudieron mencionar al menos un antagonista de esa identidad colectiva; $57 \%$ de estos afirmaron conocer las tácticas de acción colectiva empleadas por el grupo y destaca que la mayoría tiene sólo conocimiento sobre el repertorio de acción colectiva de índole hacktivista (57.1\%) y únicamente una minoría relaciona las actividades de Anonymous con el repertorio clásico de la acción colectiva (9.8\%).

Un fenómeno similar se observa en el conocimiento de la muestra sobre los objetivos de Anonymous ${ }^{21}: 72.5 \%$ de esta población piensa que Anonymous busca defender la libertad de expresión y $68 \%$ lo relaciona por defender las libertades en Internet, en contraste, la identificación de Anonymous con objetivos cercanos al activismo clásico o de la Nueva Izquierda es muy inferior ${ }^{22}$, con respecto a los ciberlibertarios.

En general, la dimensión cognitiva, analizada a través de su subíndice en donde se conjugan las tres categorías analíticas (marco de injustica, agencia e identidad), fue el más alto de los tres (cognitivo, afectivo, participativo), con una media poblacional de 2.4, en una escala de 5 a 5.

Por su parte, los datos obtenidos a partir de medir la dimensión afectiva muestran que la identificación y los lazos afectivos y de solidaridad entre Anonymous y estas audiencias es bajo: los estudiantes se identifican con Anonymous en promedio en 1.7 dentro de una escala del 0 al 5 y tan solo $44 \%$ de quienes tienen conocimiento de esta identidad colectiva sostienen tener sentimientos de solidaridad y/o positivos hacia ellos (véase Figura 2).

\section{Tipo de sentimientos hacia Anonymous}
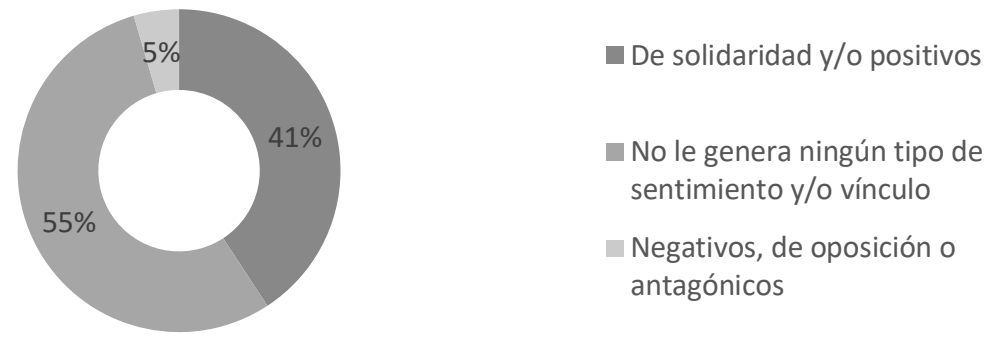

Figura 2. Tipo de sentimientos hacia Anonymous. De elaboración propia

Los resultados que se obtuvieron mediante el subíndice correspondiente a esta dimensión ilustran el bajo vínculo afectivo entre los protagonistas y sus auditorios: en promedio, a partir

\footnotetext{
${ }^{21} \mathrm{Al}$ ser una variable multi-respuesta, cada indicador puede llegar al $100 \%$.

${ }^{22}$ El indicador que reporto un nivel más alto en este tipo de objetivos fue el de relacionar a Anonymous con la defensa de los derechos humanos (43.3\%).
} 
Perera Ramos, R. (2019)

Comunicación y acción colectiva. Estudio de caso de la resonancia en estudiantes universitarios de los marcos movilizadores de Anonymous

pp. $75 / 107$

de medir las siete variables correspondientes a esta dimensión, los estudiantes muestran una media de 1.7 , dentro de una escala del -5 al 5

En cuanto a la dimensión participativa, esta es la que obtuvo los resultados más bajos: en una escala del 0 al 5 los estudiantes se muestran interesado en participar con Anonymous en una media de 1.8, tan sólo tan sólo $16.7 \%$ se mostró altamente interesado en participar con la identidad colectiva y en contraste $34.1 \%$ de la población no tiene ningún interés en participar con este colectivo.

Asimismo, tan sólo uno de cada diez estudiantes (10.3\%) ha participado, apoyado o promovido alguna acción colectiva de Anonymous y la mayoría de estos sólo lo ha hecho participando en foros de discusión en línea o posteando contenidos del colectivo en sus redes sociodigitales (véase Figura 3). En suma, al medir todas las categorías analíticas del subíndice de participación se halló una media de tan sólo un punto, en una escala del 0 al 5.

En total el Índice de Resonancia del Marco de Acción colectiva de Anonymous obtuvo una media de 1.7, en una escala de -5 a 5 . En consecuencia, el siguiente paso fue el de indagar cuáles eran las mediaciones de las audiencias que afectaban en su nivel de resonancia, con respecto a estos marcos de acción.

\section{Participación en acciones colectivas de Anonymous}
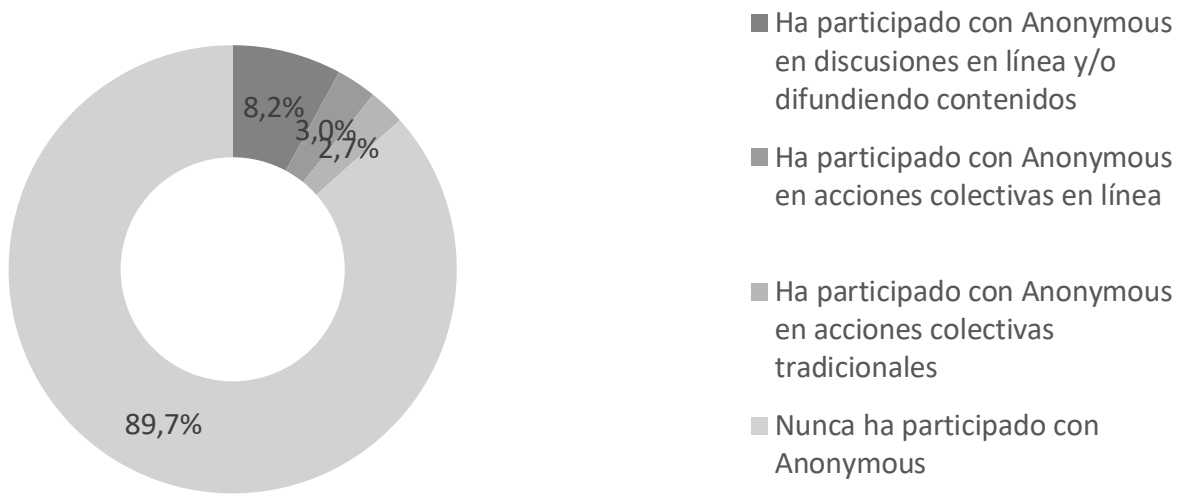

Figura 3. Participación de los encuestados en acciones colectivas de Anonymous o en apoyo. De elaboración propia

\subsection{Mediaciones y resonancia}

En los últimos años el uso de Internet por parte de los MS y sus agrupaciones se ha vuelto una constante, lo que ha incrementado el uso e importancia de este medio en la movilización social. Es decir, la utilización de Internet por parte de los MS es ya una práctica cotidiana para estas organizaciones, la cual pareciera ser irreversible. 
Perera Ramos, R. (2019)

Comunicación y acción colectiva. Estudio de caso de la resonancia en estudiantes universitarios de los marcos movilizadores de Anonymous

pp. $75 / 107$

Internet ya no es un medio por el que puedan optar o no los activistas, ya no es una elección, se ha vuelto una herramienta indispensable para estos grupos reivindicativos (al menos en esta parte occidental del mundo) y esta dependencia al medio observa una tendencia en crecimiento a la par de que se estrechan las brechas digitales e Internet se convierte, cada vez más, en el centro gravitatorio de la sociedad contemporánea, dando paso a una sociedad digital.

En consecuencia, se vuelve pertinente y necesario estudiar cuáles son las mediaciones que intervienen en las diferentes lecturas que los usuarios hacen de Internet y enfocarse en este objeto de estudio, esto es, la resonancia de los MAC en sus audiencias. En este caso, la investigación contempló tres tipos de mediaciones que se pensaron podrían ser estadísticamente significativas para explicar las variaciones en el grado de resonancia de las

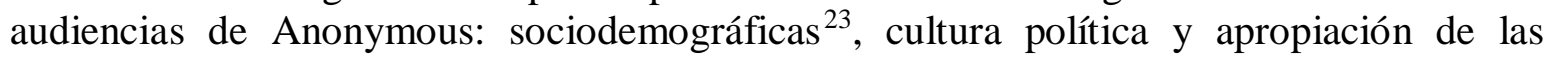
tecnologías.

De esta forma, se hicieron pruebas de correlación entre los índices construidos, así como de las variables sociodemográficas, en las que se encontró que tanto el Índice de Actitudes y Partición Política No Institucional y el Índice de Apropiación de Internet, se relacionan significativamente con el Índice de Resonancia del Marco de Acción Colectiva de Anonymous.

En ambos casos mostraron ser las correlaciones significativas a un nivel de 0.01 y con un coeficiente en la correlación de Pearson medianamente alto (.575 y .566, respectivamente). Asimismo, la variable ideología política también resultó ser estadísticamente significativa (a partir de una prueba unilateral sig $=.000)$ y con un coeficiente medianamente alto $(-.449)^{24}$.

En lo que se refiere a las variables de tipo sociodemográficas, sólo las variables de edad y semestre resultaron tener un nivel de significancia considerable para ser tomadas en cuentas (sig. unilateral $=.000$ y coeficiente de Pearson $=.296)^{25}$.

Así, a partir de las pruebas de correlación se elaboró un modelo lineal de regresión múltiple, al tomar como variable dependiente al Índice de Resonancia del Marco de Acción Colectiva de Anonymous y como independientes a los otros dos índices restantes que mostraron una correlación estadísticamente significativa. Al modelo de regresión también se le añadió la variable de ideología política y la de edad.

\footnotetext{
${ }^{23}$ Las variables de este tipo que se incluyeron fueron: sexo, edad, semestre, facultad o escuela en donde estudia y nivel socioeconómico.

${ }^{24}$ El coeficiente de Pearson tiene un resultado negativo debido a que la variable fue medida a partir de un auto posicionamiento ideológico en donde cero representó izquierda extrema y seis extrema derecha. Por lo que el MAC de Anonymous se muestra más resonante mientras sus audiencias se acerquen, en mayor medida, a la ideología política de izquierda.

${ }^{25}$ Aunque tanto la edad, como semestre mostraron ser estadísticamente significativas, se decidió eliminar a la variable semestre del modelo de regresión múltiple, debido a que estas dos variables se solapan.
} 
En el modelo se observó que todas las variables independientes consideradas, fueron estadísticamente significativas a un nivel de 0.01 por lo que están linealmente relacionadas las variables dependientes con la independiente y todos ellas guardan una relación directa, excepto la de ideología política (la cual es una relación inversa) con el nivel de resonancia del enmarcado de Anonymous en sus audiencias.

En general, las cuatro variables independientes, en conjunto, explican o predicen $49.2 \%$ el grado de resonancia que tienen los universitarios encuestados del MAC de Anonymous y el modelo presenta un alto grado de correlación (.701).

Por su parte, a través de la tabla de coeficientes, se observa que el Índice de Mediación Tecnológica, es la que tiene mayor peso explicativo en el modelo, seguido del de Actitudes y Partición Política No Institucional.

Así, a partir de los coeficientes no estandarizados se entiende que, por cada unidad que aumente el Índice de Mediación Tecnológica, en un individuo, su resonancia del marco aumentará en 0.506. El aumento por cada unidad en el Índice de Actitudes y Partición Política No Institucional, significará un aumento en la resonancia del enmarcado de Anonymous en 0.260; por cada año que es mayor un estudiante se estima que subirá su nivel de resonancia en 0.086. Por último, mientras más se acerquen los universitarios a la extrema derecha, por cada unidad de cambio hacia esa ideología política, se predice una disminución de la resonancia del MAC de Anonymous en 0.139.

En conjunto la ecuación lineal de predicción se expresa de la siguiente forma (donde Y representa el índice de Resonancia del Marco de Acción Colectiva de Anonymous y las X, cada una de las cuatro variables independientes):

$Y=-.442+.506 X_{1}+.260 X_{2}+.086 X_{3}+(-.139) X_{4}$

\section{Conclusiones}

En este trabajo se presentó un acercamiento a la teoría de los MAC y de las identidades colectivas desde una mirada comunicológica, con el fin de analizar algunos aspectos relevantes de la acción colectiva, que no han sido suficientemente tratados tanto teórica como empíricamente.

En particular, el estudio se centró en el concepto de resonancia del MAC en las audiencias de los grupos reivindicativos, con el objetivo de observar las capacidades que ofrece Internet en los procesos comunicativos de los MS, los cuales podrían otorgarles un mayor grado de resonancia a partir de las oportunidades estructurales de mediación, que les ofrece este medio.

Asimismo, se buscó, a partir de los datos arrojados en el estudio de caso, observar cuáles son las mediaciones de los auditorios, más relevantes, que influyen en su grado de resonancia con respecto a los marcos diseminados en el ciberespacio por parte de los grupos contenciosos y que utilizan a Internet como principal o única herramienta de mediación. 
Perera Ramos, R. (2019)

Comunicación y acción colectiva. Estudio de caso de la resonancia en estudiantes universitarios de los marcos movilizadores de Anonymous

pp. $75 / 107$

De esta forma, los datos del estudio de caso (los cuales, si bien no pueden ser generalizados, ya que sólo comprenden un caso simple y dado el carácter exploratorio de la pesquisa, difícilmente pueden ser comparados con otros casos de estudio similares) arrojaron, de manera general, que la resonancia del enmarcado de Anonymous en las audiencias estudiadas es baja, por lo que se podría inferir que Internet no representa una herramienta poderosa, que coadyuve a generar una resonancia alta con sus audiencias. Sin embargo, la lectura de estos hallazgos debe ser hecha a la luz de contextualizar a las audiencias estudiadas.

Por un lado, estas audiencias eran entre infantes y preadolescentes cuando el ciclo de visibilidad de Anonymous comenzó (edad en la que el interés sobre los asuntos públicos y políticos se encuentra todavía en desarrollo). Por otro lado, es importante destacar que en estas audiencias se podrían encontrar restricciones fenomenológicas más amplias, con respecto a estudiantes estadounidenses o de Europa occidental, al considerar que aunque Anonymous es una red de acción transnacional, tiene una marcada denominación de origen en Estados Unidos y el Reino Unido, siendo así que el mundo de la vida entre activistas del primer mundo y estudiantes del tercer mundo se podría encontrar bastante alejado, a lo que se le añade la restricción propias del lenguaje, la cual podría ser una mediación importante en la capacidad de resonancia de los MAC.

Un enfoque más preciso en las restricciones del lenguaje, como una mediación importante a considerar y dado el fenómeno de transnacionalización de los MS en la actualidad (Tilly y Wood, 2010), podría ser parte de futuras investigaciones, no sólo en lo que se refiere a la resonancias de los MAC, sino como una mediación que también intervine, de forma transversal en la apropiación de las TIC (González, Hugues y Becerra , 2018) y al considerar que el inglés se ha convertido en la lengua franca tanto en el propio medio, como en un mundo cada vez más globalizado.

En este sentido, a partir de interpretar los hallazgos, desde el contexto señalado, se podría concluir que aunque los datos arrojan un nivel de resonancia medianamente bajo, estos pueden ser leídos como medianamente altos, así como se podría inferir sobre la alta capacidad de resonancia a largo plazo de la comunicación automediada por Internet, debido a que aunque el enmarcado hacktivista dejó de ser el marco dominante en Anonymous, desde hace un lustro, este sigue siendo el que tiene mayor presencia en el imaginario colectivo de sus audiencias.

Así, un buen conocimiento y uso de las oportunidades estructurales de mediación que ofrecen los medios digitales se podría traducir en marcos resonantes con efectos a largo plazo, como lo demuestra Anonymous en su fase de visibilidad liderada por la facción hacktivista.

En contraste, se observa que una comunicación a través del ciberespacio más limitada, como la efectuado por la actual vanguardia ciberactivista de Anonymous, muestra una resonancia menor. En este caso, se puede concluir que una mayor o menor apropiación por parte de los actores colectivos de las TIC, podría incidir directamente en sus niveles de resonancia con las audiencias. 
Perera Ramos, R. (2019)

Comunicación y acción colectiva. Estudio de caso de la resonancia en estudiantes universitarios de los marcos movilizadores de Anonymous

pp. $75 / 107$

Por el otro lado, desde el punto de vista de las audiencias, se comprobó la hipótesis de que el nivel de apropiación que observan estas de las TIC, también incide directamente en su grado de resonancia con respecto a un MAC (como el de Anonymous) diseminado preponderantemente por el ciberespacio. En este sentido, el nivel de apropiación se observa como la variable de mayor peso en este proceso comunicativo y el cual converge con la edad de las audiencias, lo que refuerza los hallazgos de Lemus y Gonzáles (2018), quienes concluyen que existe una relación entre la edad y los niveles de apropiación de las TIC.

Si bien queda demostrado en este estudio que la apropiación de las TIC, como mediación, intervine en el grado de resonancia de los MAC en las audiencias, es importante destacar que podrían existir otras mediaciones con igual o mayor peso, dependiendo del caso de estudio, es decir, del actor colectivo y las audiencias que se estudien.

En este mismo orden de ideas, aunque el nivel de apropiación de las TIC por parte de los MS podría ser una variable importante a considerar en cuanto al nivel de resonancia que podría evocar en sus audiencias, este estudio no considera otros aspectos de orden más cualitativos, que pudieran ser fenomenológicamente más trascendentes, como las ideas, los objetivos, el reconocimiento que se busca, etc. En suma, la calidad sustantiva del MAC, la forma de enmarcarlo y comunicarlo por parte de los grupos contenciosos, lo cual permita conectar con y llevar hacia la acción a las audiencias.

Lo que se buscó en este artículo fue observar las capacidades potenciales de resonancia que ofrece Internet como herramienta de automediación de los MS y su apropiación como una de las mediaciones relevantes a considerar para tales fines. Realizar más investigaciones de este tipo, así como refinar los instrumentos y las estrategias metodológicas, principalmente a partir de la combinación de técnicas cualitativas y cuantitativas y entablar un mayor diálogo entre las disciplinas de las ciencias sociales, conducirá hacia un mejor entendimiento sobre este tema de estudio, aún poco explorado.

Con base en lo anterior este trabajo puede considerarse como una investigación exploratoria que puede ser robustecida con la profundidad que ofrecen las técnicas cualitativas, principalmente en lo que se refiere al análisis de la resonancia en las audiencias.

Por último, como ya se ha expresado, aunque la investigación guarda una validez interna, sus resultados difícilmente pueden ser generalizados debido a las propias limitaciones de la estrategia metodológica empleada. Sin embargo, puede servir como una base para posteriores estudios que estén interesado en observar la relación entre la apropiación de las TIC y la resonancia de los MAC de los MS, lo que permitiría refutar o darle una validez externa a lo que aquí se ha presentado.

\section{Referencias}

Ariño, A. (2009). El movimiento Open. La creación de un dominio público en la era digital, España: Universidad de Valencia. 
Perera Ramos, R. (2019)

Comunicación y acción colectiva. Estudio de caso de la resonancia en estudiantes universitarios de los marcos movilizadores de Anonymous

pp. $75 / 107$

Asenbaum, H. (2017). "Cyborg activism: Exploring the reconfigurations of democratic subjectivity in Anonymous”, New Media \& Society, Vol. 20, No. 4, pp. 1543-1563.

Ashley, L. y Olson, B. (1998). “Constructing Reality: Print Media’s Framing of the Women’s Movement, 1966-1986”, Journalism and Mass Communication Quarterly, Vol. 75, No. 2, pp. 263-277.

Atton, C. (2003). "Reshaping social movement media for a new millennium”, Social Movement Studies, Vol. 2, No. 1, pp. 3-15.

Barandiaran, X. (2003). Activismo digital y telemático. Poder y contrapoder en el ciberespacio. v.1.1. Metabolik BioHacklab. Disponible en Internet: http://sindominio.net/ xabier/textos/adt/adt.pdf [Consulta 16 de febrero, 2017]

Battocchio, S. (2014). Transformaciones de la movilización social a través de la red. El caso de Anonymous. (Tesis de Maestría). Universidad Complutense de Madrid.

Blee, K. y McDowell, A. (2012) “Social movement audiences”, Sociological Forum, Vol. 27, No.1, pp. 1-20.

Cammaerts, B. (2012). "Protest logics and the mediation opportunity structure”, European Journal of Communication, vol. 27, No.2, pp. 117-134.

Cammaerts, B. Mattoni, A. y McCurdy, P. (edits.) (2013). Mediation and protest movements, Estados Unidos: Chicago University Press.

Candón, J. (2010). Internet en movimiento. Nuevos movimientos sociales y nuevos medios en la sociedad de la información (Tesis de Doctorado). Universidad Complutense de Madrid.

Carty, V. (2015). Social movements and new technology, Estados Unidos: Westview Press.

Castells, Manuel (2001). La Galaxia Internet. Reflexiones sobre Internet, Empresa y Sociedad. Barcelona: Plaza y Janés Editores S.A.

Coleman, G. (2016). Las mil caras de Anonymous, España: Arpa Editores.

Crovi, D. (coord.) (2016). Redes sociales digitales. Lugar de encuentro, expresión y organización para los jóvenes, México: UNAM.

Crovi, D. (2017). "Prácticas de comunicación e interacción en la cultura digital”, en Cabello, R. y López, A. (edits.). Contribuciones al estudio de procesos de apropiación de tecnologías, Argentina: Ediciones del Gato gris.

Crovi, D. (coord.) (2018). Prácticas comunicativas en entornos digitales, México: UNAM.

Chihu A.(coord.) (2006). El “análisis de los marcos” en la sociología de los movimientos sociales, México: Miguel ángel Porrua-UAM.

Díaz, L. (2011). La observación, México: UNAM. 
Perera Ramos, R. (2019)

Comunicación y acción colectiva. Estudio de caso de la resonancia en estudiantes universitarios de los marcos movilizadores de Anonymous

pp. $75 / 107$

Friedman, T. (2005). Electronic dreams: computers in american culture, Estados Unidos: New York University Press.

Gitlin, T. (1980). The whole world is watching. Mass media in the making and unmaking of the new left, Estados Unidos: University of California Press.

González, M; Hugues, E; y Becerra, M. (2018). "El nivel socioeconómico y el dominio del idioma inglés, elementos de acceso y ampliación de la brecha en la cultura digital" en Crovi, D. (coord.)._Prácticas comunicativas en entornos digitales, México: UNAM.

Hai-Jew, Shalin (2013). "Action potentials: Extrapolating an ideology from the Anonymous hacker socio-political movement (a qualitative meta-analysis)", en Akrivopoulou, C. y Garipidis, N. (edits.). Digital Democracy and the Impact of Technology on Governance and Politics: New Globalized Practices, Estados Unidos: Information Science Reference

Hall, S. (1982). "The rediscovery of ideology: Return of the repressed in media studies" en Gurevitch, M., Bennett, T., Curran, J. y Woollacott, J. (eds). Culture, Society and the media, Nueva York: Methuen.

Halloran, J.; Elliott, P. y Murdock, G. (1970). Demonstrations and communication. A case study, Reino Unido: Penguin Books.

Hepburn, K. (2013). “Introduction” en Cammaerts, B.; Mattoni, A. y McCurdy, P. (edits). Mediation and protest movements, Estados Unidos: Chicago University Press.

Hernández, R.; Fernández-Collado, C.; Baptista P. (2003). Metodología de la investigación, México: McGraw Hill Interamericana.

Hunt, S.; Benford, R. y Snow, D. (1994). "Marcos de acción colectiva y campos de identidad en la construcción social de los movimientos” en Laraña, E. y Gusfield, J. Los nuevos movimientos sociales. De la ideología a la identidad, Madrid: Centro de Investigaciones Sociológicas.

Hurst, S. (2013). Examining Hacktivism as Performance Through the Electronic Disturbance Theater and Anonymous (Tesis de Maestría). Universidad del Estado de Florida.

INEGI (2018). Estadísticas a propósito del día mundial de internet (17 de mayo), México: Instituto Nacional de Estadística y Geografía. Disponible en Internet: http://www.beta.inegi.org.mx/contenidos/saladeprensa/aproposito/2018/internet2018_Nal.p df [Consulta 21 de noviembre, 2018]

Jensen, Klaus. (1991). "When is meaning? Communication theory, pragmatism and media reception”, Annals of the International Communication Association, Vol. 14, No.1, pp. 3-32.

Knappenberger, B. (productor y director) (2012). We Are Legion: The Story of the Hacktivists, [cinta documental], Estados Unidos: Luminant Media. 
Perera Ramos, R. (2019)

Comunicación y acción colectiva. Estudio de caso de la resonancia en estudiantes universitarios de los marcos movilizadores de Anonymous

pp. $75 / 107$

Lemus, C. y González, M. (2018). "Elementos para comprender la interacción juvenil en las redes sociales digitales”, en Crovi, D. (coord.) (2018). Prácticas comunicativas en entornos digitales, México: UNAM.

Levy, S. (1994). Hackers. Heroes of computer revolution, Estados Unidos: Dell Publishing Group.

Ludlow, Peter (edit.) (2001). Crypto anarchy, cyberstates, and pirate utopias, Estados Unidos: The IMT Press.

Marwick, A. y boyd, d. (2010). "I tweet honestly, I tweet passionately: Twitter users, context collapse, and the imagined audience”, New Media and Society, Vol. 13, No.1, pp. 114-133.

Mattoni, A. y Treré, E. (2014). "Media practices, mediation processes, and mediatization in the study of social movements”, Communication Theory, No.24, pp. 252-271.

Martín-Barbero, J. (1991). De los medios a las mediaciones. Comunicación, cultura y hegemonía, México: Editorial Gustavo Gili.

Melucci, A. (1996). Challenging codes: collective action in the information age, Gran Bretaña: Cambridge University Press.

Melucci, Alberto (1989). Nomads of the present, Philadelphia: Temple University Press.

Melucci, A. (2001). A invençao do presente: movimientos sociais nas sociedades complexas, Rio de Janeiro: Editora Vozes

Natal, A. y Perera, R. (2014). "Hacktivismo y participación política” en Natal A., Benítez, M. y Ortiz, G. Ciudadanía Digital, México: Universidad Autónoma Metropolitana-Juan Pablos.

Oliver, P. y Maney, G. (2000). "Political Processes and Local Newsarticle Coverage of Protest Events: From Selection Bias to Triadic Interactions”. American Journal of Sociology, Vol. 106(2): 463-505.

Olson, P. (2012). We Are Anonymous: Inside the Hacker World of LulzSec, Anonymous, and the Global Cyber Insurgency, Nueva York: Little Brown and Company.

Pecourt, J. (2016). "Anonymous y el underground digital: aproximación al análisis de un objeto socio-digital”, Revista Española de Sociología, Vol. 25, No.1, pp. 133-149.

Perera, R. (2018). “Movimientos conectivos y redes sociales: análisis de la Red Anonymous en Twitter” en Crovi, D. (coord.). Prácticas comunicativas en entornos digitales, México: UNAM.

Sáenz, A. y Tamez, G. (coords.) (2014). Métodos y técnicas cualitativas y cuantitativas aplicables a la investigación en ciencias sociales, México: Tirant Humanidades. 
Perera Ramos, R. (2019)

Comunicación y acción colectiva. Estudio de caso de la resonancia en estudiantes universitarios de los marcos movilizadores de Anonymous

pp. $75 / 107$

Sádaba, I. (2012). “Acción colectiva y movimientos sociales en las redes digitales. Aspectos históricos y metodológicos”, ARBOR Ciencia, Pensamiento y Cultura, vol. 188, pp. 755794.

Samuel, A. (2004). Hacktivism and the future of political participation (Tesis de Doctorado), Universidad de Harvard

Shirky, C. (2011). "The political power of social media technology, the public sphere, and political change”, Foreign Affairs, Vol. 90, No. 1, pp. 28-41.

Snow, D. y Benford, R. (2006). "Ideología, resonancia de marcos y movilización de los participantes" en Chihu, A. (coord.). El "análisis de los marcos” en la sociología de los movimientos sociales, México: Miguel ángel Porrua-UAM.

Snow, D.; Rochford, B.; Worden, S. y Benford R. (2006). "Procesos de alineamiento de marcos, micromovilización y participación en movimientos" en Chihu, A. (coord.). El "análisis de los marcos" en la sociología de los movimientos sociales, México: Miguel ángel Porrua-UAM.

Tilly, C. (1998). Popular Contention in Great Britain, 1758-1834, Harvard: Harvard University Press.

Tilly, C. (2006). Regimes and repertories, Estados Unidos: The University of Chicago Press.

Tilly, C. y Wood, L. (2010). Los movimientos sociales, 1768-2008. Desde sus orígenes a Facebook, Barcelona: Editorial Crítica.

Torres M. (2013). “Siete lecciones no aprendidas sobre Anonymous”, Instituto Español de Estudios Estratégicos, Documento de Opinión (122/2013).

Van Dijk, T. (1988). News analysis: Case studies of international and national news in the press, Nueva Jersey: Lawrence Erlbaum Associates Publishers.

Van Dijk, Teun (1997). “Discurso, cognición y sociedad”, Signos. Teoría y práctica de la educación, 8, No. 22, pp. 66-74.

Van Dijk, T. (2003). "La multidisciplinariedad del análisis crítico del discurso: un alegato en favor de la diversidad” en Wodak, R. y Meyer, M. (comps.) Métodos de análisis crítico del discurso, Barcelona, Editorial Gedisa: 143-177.

Van Dijk, T. (2004). "Discurso y dominación”, Grandes Conferencias en la Facultad de Ciencias Humanas, $\mathrm{N}^{\circ}$ 4, Universidad de Colombia, pp. 1-27

Van Dijk, T. (2005). “Ideología y análisis del discruso”, Utopía y Praxis Latinoamericana, vol. 10, No. 29, pp. 9-36.

Van Zoonen, L. (1992). “Gender and Film”, Journal of Communication, Vol. 42, No. 4, pp. 180-185. 
Perera Ramos, R. (2019)

Comunicación y acción colectiva. Estudio de caso de la resonancia en estudiantes universitarios de los marcos movilizadores de Anonymous

pp. $75 / 107$

Vliegenthart, R. y Walgrave, S. (2012). "The interdependency of mass media and social movements” en H. A. Semetko y M. Scammell. The SAGE handbook of political communication, Londres: SAGE Publications Ltd.

White, R. (1997). "La audiencia como creadora de cultura y textos alternativos", Comunicación y Sociedad, No. 29, pp. 23-54.

Yin, R. (1994). Case study research Design and Methods, Londres: Sage Publications. 